Synthesis, part of a Special Feature on Restoring Riverine Landscapes

\title{
Restoring Environmental Flows by Modifying Dam Operations
}

\author{
Brian D. Richter $^{1}$ and Gregory A. Thomas ${ }^{2}$
}

\begin{abstract}
The construction of new dams has become one of the most controversial issues in global efforts to alleviate poverty, improve human health, and strengthen regional economies. Unfortunately, this controversy has overshadowed the tremendous opportunity that exists for modifying the operations of existing dams to recover many of the environmental and social benefits of healthy ecosystems that have been compromised by present modes of dam operation. The potential benefits of dam "re-operation" include recovery of fish, shellfish, and other wildlife populations valued both commercially and recreationally, including estuarine species; reactivation of the flood storage and water purification benefits that occur when floods are allowed to flow into floodplain forests and wetlands; regaining some semblance of the naturally dynamic balance between river erosion and sedimentation that shapes physical habitat complexity, and arresting problems associated with geomorphic imbalances; cultural and spiritual uses of rivers; and many other socially valued products and services. This paper describes an assessment framework that can be used to evaluate the benefits that might be restored through dam re-operation. Assessing the potential benefits of dam re-operation begins by characterizing the dam's effects on the river flow regime, and formulating hypotheses about the ecological and social benefits that might be restored by releasing water from the dam in a manner that more closely resembles natural flow patterns. These hypotheses can be tested by implementing a re-operation plan, tracking the response of the ecosystem, and continually refining dam operations through adaptive management. The paper highlights a number of land and water management strategies useful in implementing a dam re-operation plan, with reference to a variety of management contexts ranging from individual dams to cascades of dams along a river to regional energy grids. Because many of the suggested strategies for dam re-operation are predicated on changes in the end-use of the water, such as reductions in urban or agricultural water use during droughts, a systemic perspective of entire water management systems will be required to attain the fullest possible benefits of dam re-operations.
\end{abstract}

Key Words: dams; dam re-operation; environmentalflows; flood control dams; flow restoration; hydrologic alteration; hydropower dams; irrigation dams.

\section{INTRODUCTION}

During the latter half of the 20th century, two large dams were built each day, on average (WCD 2000). By 2000, the number of large dams had climbed to more than 47,000, and an additional 800,000 smaller dams now block the flow of the world's rivers (McCully 1996, Rosenberg et al. 2000, WCD 2000). Globally, over half of the 292 large river systems have been affected by dams (Nilsson et al. 2005). Most of these dams provide substantial benefits to human societies and their economies. Hydroelectric power dams currently provide $19 \%$ of the world's electricity supply; one in three nations depends on hydropower to meet at least half of its electricity demands (WCD 2000). By capturing and storing river flows for later use, dams and reservoirs have contributed to the global supply of water for urban, industrial, and agricultural uses. Worldwide, water demands have roughly tripled since 1950, and dams have helped satisfy that demand. About half of the world's large dams were built solely or primarily for irrigation. Today, large dams are estimated to contribute directly to $12-16 \%$ of global food production (WCD 2000).

However, damming of the world's rivers has come at great cost to their ecological health and ecosystem services valued by society (WCD 2000, Postel and Richter 2003, WWF 2004, MEA 2005). Dams have 
considerable influence on downstream river ecosystems, in many cases extending for hundreds of kilometers below a dam (Collier et al. 1996, McCully 1996, Willis and Griggs 2003). Daminduced changes affect water temperature (Clarkson and Childs 2000, Todd et al. 2005) and chemistry (Ahearn et al. 2005), sediment transport (Williams and Wolman 1984, Vorosmarty et al. 2003), floodplain vegetation communities (Magilligan et al. 2003, Shafroth et al. 2001, Tockner and Stanford 2002), and even downstream estuaries, deltas, and coastal zones by modifying salinity patterns, nutrient delivery, and the transport of sediment that builds deltas, beaches, and sandbars (Olsen et al. 2006).

Of all the environmental changes wrought by dam construction and operation, the alteration of natural water flow regimes has had the most pervasive and damaging effects on river ecosystems and species (Poff et al. 1997, Postel and Richter 2003). Below we discuss the ways that dam operations induce hydrologic changes, the nature of which is strongly influenced by the operating purposes of the dam. Dams can heavily modify the volume of water flowing downstream, change the timing, frequency, and duration of high and low flows, and alter the natural rates at which rivers rise and fall during runoff events. Although much has been written about the ecological consequences of hydrologic alteration, Bunn and Arthington (2002) summarize their review of this literature by highlighting four primary ecological impacts associated with flow alteration: (1) because river flow shapes physical habitats such as riffles, pools, and bars in rivers and floodplains, and thereby determines biotic composition, flow alteration can lead to severely modified channel and floodplain habitats; (2) aquatic species have evolved life history strategies, such as their timing of reproduction, in direct response to natural flow regimes, which can be desynchronized through flow alteration; (3) many species are highly dependent upon lateral and longitudinal hydraulic connectivity, which can be broken through flow alteration; and (4) the invasion of exotic and introduced species in river systems can be facilitated by flow alteration.

In this paper we discuss opportunities and strategies for modifying dam operations, hereafter referred to as "re-operation" for restoring natural flow regimes and associated ecosystem health and services, which are important to society. We focus on restoration of natural flow regimes as a general principle of dam re-operation because sustaining river-dependent biodiversity and ecosystem services requires maintaining some semblance of natural flow characteristics (Poff et al. 1997, Richter et al. 2003, Postel and Richter 2003).

It is important to acknowledge that given multiple and often competing objectives imposed upon any water management system, both the volume and timing of water releases from a dam will likely differ from natural flows. The challenge for the water manager is to use the available water and infrastructure to meet an array of objectives, including environmental flow releases, in an optimal manner. In this context it is critically important that scientists prioritize characteristics of natural flow regimes that are likely to yield the greatest ecological benefit, through environmental flow assessment (King et al. 2003, Richter et al. 2006). Case studies from river basins around the world suggest that significant ecological benefit can be recovered through carefully targeted, partial restoration of natural flow regimes (Postel and Richter 2003).

Opportunities for recovering social and environmental benefits through dam re-operation will be constrained by existing water allocation entitlements, biological and physical conditions, socioeconomic limitations, political or legal impediments, and the physical features of existing dams. A basic premise of our approach is that dams must be viewed as components of integrated water management systems, such as irrigation or urban water supply systems or energy grids. It is only through this holistic perspective that the full range of opportunities for dam re-operations can be realized; many of the strategies we highlight in this paper are predicated upon the ability to change the way that water is being used within a broader water management system.

We begin by describing the primary ways in which dams of various types alter the natural flow regime. We then offer a conceptual framework for assessing opportunities and constraints in restoring natural flow characteristics, and conclude by describing a variety of dam re-operation strategies that can be used to restore environmental flows and associated benefits. 


\section{DAM-INDUCED HYDROLOGIC ALTERATION}

Because dam re-operation projects will usually involve restoring natural flow conditions to some degree, it is important to understand how different types of dams will alter natural flow regimes in different ways. The nature and magnitude of these alterations will dictate the type of re-operation strategies that will be necessary to restore environmental flows. To facilitate our discussion of hydrologic alteration in this paper we will use a simple "environmental flow vocabulary" developed by Richter et al. (2005): extreme low flows, low flows, high-flow pulses, small floods, and large floods (Table 1). This flow vocabulary can be found in the "Indicators of Hydrologic Alteration" (IHA) software program (TNC 2005), which we have used in assessing hydrologic changes in the case studies referenced in this paper. Table 1 provides a summary of ecological roles that each of the five environmental flow components might play in a given river ecosystem. Dams will alter the five environmental flow components in differing ways, owing largely to differences in the ways that a dam is operated to provide various services including flood control, hydropower generation, and water supply.

\section{Flood control dams}

The obvious goal of a flood-control dam is to capture some portion of in-flowing floodwaters, and subsequently release that water at a lower discharge level than would have occurred otherwise. Therefore, the general hydrologic effect of a floodcontrol dam is to chop off the peak, and then taper down to a lower level of water release from the dam until the floodwaters have been fully discharged from the reservoir (Fig. 1). The ecological consequences of a flood-control dam are usually related to the elimination of small floods, i.e., 2- to $10-\mathrm{yr}$ recurrence interval, and all but the most extreme large floods $(>50 \mathrm{yr})$, as well as the introduction of artificially long high-flow pulses following flood peaks.

\section{Hydropower dams}

Many hydropower dams are operated as "run-ofthe-river" facilities with little water storage capacity relative to the volume of flow in the river, resulting in only minor alterations to flow regimes. However, large hydropower dams with considerable reservoir storage capacity are able to capture high water flows and store them for later use, specifically to generate hydro-electric power as needed to meet local or regional energy demand patterns. This can result in lowered flood peaks, followed by a rapidly fluctuating hydrologic pattern in the downstream river corresponding to alternating periods of power generation. These episodes of power generation are followed by periods in which dam releases may be largely or completely curtailed to allow the reservoir to refill in-between power-generation cycles, thus producing a blocky or saw blade appearance in the outflow hydrograph (Fig. 2). The rapid fluctuations in water levels associated with hydropower operations can cause considerable ecological damage, as it can leave slow-moving aquatic animals such as mussels stranded when levels drop, or sweep them away when levels rise too quickly. When the dam is generating power, water releases through the turbines may be much higher than natural, followed by very low water releases that may drop well below natural levels. In many rivers used for hydropower generation, water flows are completely shut off during periods when reservoir levels are being restored. The ecological consequences of hydropower dams with storage capabilities are usually related to the elimination of small floods, introduction of frequent, artificial high-flow pulses, and lowering of river levels below natural low-flow levels, often to the point of artificially creating frequent occurrences of extreme low or no flow.

\section{Water supply dams}

Water supply dams are designed to capture a significant proportion of high-flow events and release water according to water demands in cities, farms, or industries. As a general rule, the greatest ecological damage is associated with dams with large storage capacity. These dams can completely rearrange seasonal patterns of water flow, such as when wet-season flows are stored for release in the dry season to support irrigated agriculture. For example, Lake Powell on the Colorado River in the 
Table 1. Summary of the five environmental flow components (EFCs) used in the Indicators of Hydrologic Alteration software, and their ecosystem influences.

\begin{tabular}{lll}
\hline \hline EFC type & Hydrologic parameters & Ecosystem influences
\end{tabular}

1. Monthly low flows

2. Extreme low flows
Mean or median values of low flows during each calendar month

\section{Subtotal 12 parameters}

Frequency of extreme low flows during each water year or season

Mean or median values of extreme low flow event:

Duration (d)

Magnitude (minimum flow during event)

Timing (Julian date of peak flow)
Provide adequate habitat for aquatic organisms

Maintain suitable water temperatures, dissolved oxygen, and water chemistry

Maintain water table levels in floodplain, soil moisture for plants

Provide drinking water for terrestrial animals

Keep fish and amphibian eggs suspended

Enable fish to move to feeding and spawning areas

Support hyporheic organisms living in saturated sediments

Enable recruitment of certain floodplain plant species

Purge invasive, introduced species from aquatic and riparian communities

Concentrate prey into limited areas to benefit predators

Subtotal 4 parameters 
3. High flow pulses

4. Small floods, i.e., 2-10 yr events
Frequency of high flow pulses during each water year or season

Mean or median values of high flow pulse event:

Duration (d)

Peak flow (maximum flow during event)

Timing (Julian date of peak flow)

Rise and fall rates

Subtotal 6 parameters

Frequency of small floods

Mean or median values of small flood event:

Duration (d)

Peak flow (maximum flow during event)

Timing (Julian date of peak flow)

Rise and fall rates
Shape physical character of river channel, including pools, riffles

Determine size of streambed substrates, e.g., sand, gravel, cobble

Prevent riparian vegetation from encroaching into channel

Restore normal water quality conditions after prolonged low flows, flushing away waste products, and pollutants

Aerate eggs in spawning gravels, prevent siltation

Maintain suitable salinity conditions in estuaries

May apply to small or large floods:

Provide migration and spawning cues for fish

Trigger new phase in life cycle, i.e., insects

Enable fish to spawn in floodplain, provide nursery area for juvenile fish

Provide new feeding opportunities for fish, waterfowl

Recharge floodplain water table

Maintain diversity in floodplain forest types through prolonged inundation, $i$. e., different plant species have different tolerances

Control distribution and abundance of plants on floodplain

Deposit nutrients on floodplain

Subtotal 6 parameters 
5. Large floods, i.e., >10-yr events

Frequency of large floods
Mean or median values of large flood
event: event:

Duration (d)

Peak flow (maximum flow during event)

Timing (Julian date of peak flow)

Rise and fall rates
May apply to small or large floods:

Maintain balance of species in aquatic and riparian communities

Create sites for recruitment of colonizing plants

Shape physical habitats of floodplain

Deposit gravel and cobbles in spawning areas

Flush organic materials such as food and woody debris such as habitat structures into channel

Purge invasive, introduced species from aquatic and riparian communities

Disburse seeds and fruits of riparian plants

Drive lateral movement of river channel, forming new habitats, e.g., secondary channels, oxbow lakes

Provide plant seedlings with prolonged access to soil moisture

\section{Subtotal 6 parameters}

Grand total 34 parameters

western United States can store the equivalent of three entire years worth of average runoff (Anderson and Woosley 2005). In many cases, the water captured by water supply dams is diverted directly from the reservoir, substantially reducing the amount of water that will flow downriver (Fig. 3 ). In some instances, no water is released from a water supply reservoir unless it is overtopped during very wet years. River flows may become unnaturally high during periods when stored water is being released for downstream uses, causing severe disruption to life cycles of aquatic and riparian organisms.

\section{CONCEPTUAL FRAMEWORK FOR DAM RE-OPERATION}

Whereas each dam re-operation project necessarily takes on a life of its own due to the unique combination of human and environmental contexts associated with individual dams, we offer here a conceptual framework for assessing the needs, opportunities, and benefits of re-operating a dam (Fig. 4). 
Fig. 1. Operation of a flood-control dam on the Green River in Kentucky, USA results in substantially lowered flood peaks, followed by extended high-flow releases of stored floodwater (based on 1978 data).

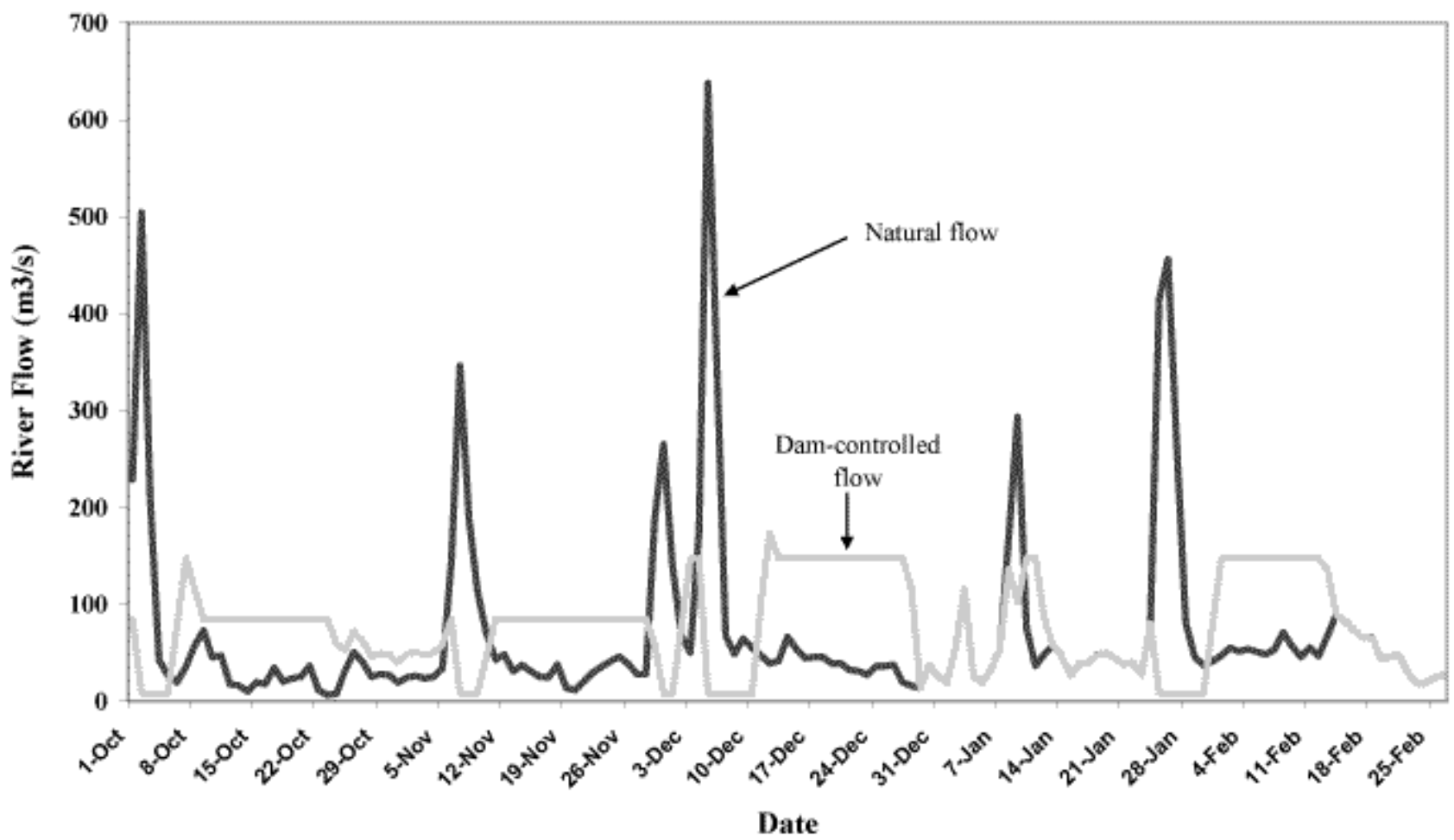

\section{Assess dam-induced hydrologic alteration}

A critically important first step in a dam re-operation project is to gain an understanding of the nature and magnitude of the hydrologic changes that have been caused by dam operations. With this understanding, scientists and water managers will be better able to understand or postulate the connections between hydrologic alteration and the ecological and social issues encountered in the next step described below. We therefore strongly recommend that an assessment of hydrologic changes associated with dam operations be conducted at the start of a dam re-operation project. The "Indicators of Hydrologic Alteration" (IHA) computer program (TNC 2005) has been designed specifically for this purpose. Such an analysis enables the project team to understand "what is broken" and may require fixing, depending upon the ecological and social goals for the project.

\section{Describe ecological and social consequences}

The hydrologic assessment described above will provide a solid foundation for evaluating the ecological and social consequences associated with dam-induced flow alteration. Many of the impacts of dam operations on the affected river ecosystem or human livelihoods will be quite well known, and many others can be surmised or hypothesized. For example, the results of a hydrologic assessment of dam impacts on the Roanoke River created the opportunity for scientists to develop a suite of ecological hypotheses linking hydrologic alterations to changes in fisheries and floodplain forests (Richter et al. 1997, Pearsall et al. 2005). In developing ecological hypotheses related to dam operations, we typically work with scientists familiar with the river of interest (or similar river types, or associated species, in the region) and discuss with them the full suite of flow alterations 
Fig. 2. Operation of a series of dams for hydropower and flood control on the Roanoke River in North Carolina, USA results in lowered flood peaks followed by frequent, short-duration high-flow pulses caused by releases of water from turbines to generate electricity. Note that flows in April drop lower than natural during a period in which dam releases are curtailed to restore reservoir levels (based on 1945 data).



identified in our hydrologic assessment. We ask whether each of the identified changes in flow characteristics could have ecological consequence, and if so, we ask them to formulate testable hypotheses describing their understanding of the flow-ecology relationships. These hypotheses provide a foundation for experimental testing during the implementation of the new dam operating scheme, as described below.

There are many different ways to solicit the input of concerned stakeholders about other social impacts and dependencies associated with dam operations (WCD 2000, Dyson et al. 2003, Olsen et al. 2006). Some of these social concerns will be directly tied to specific ecosystem conditions, such as populations of fish that are harvested commercially or for subsistence purposes, or the need for floods to inundate floodplain areas to regenerate plants used for building materials. However, other social issues including subsistence or economic uses of the river and floodplain, prevention of disease outbreaks, endangered species, flood control, recreational and tourism 
Fig. 3. Operation of an irrigation supply dam on the San Joaquin River in California, USA has severely depleted river flows.

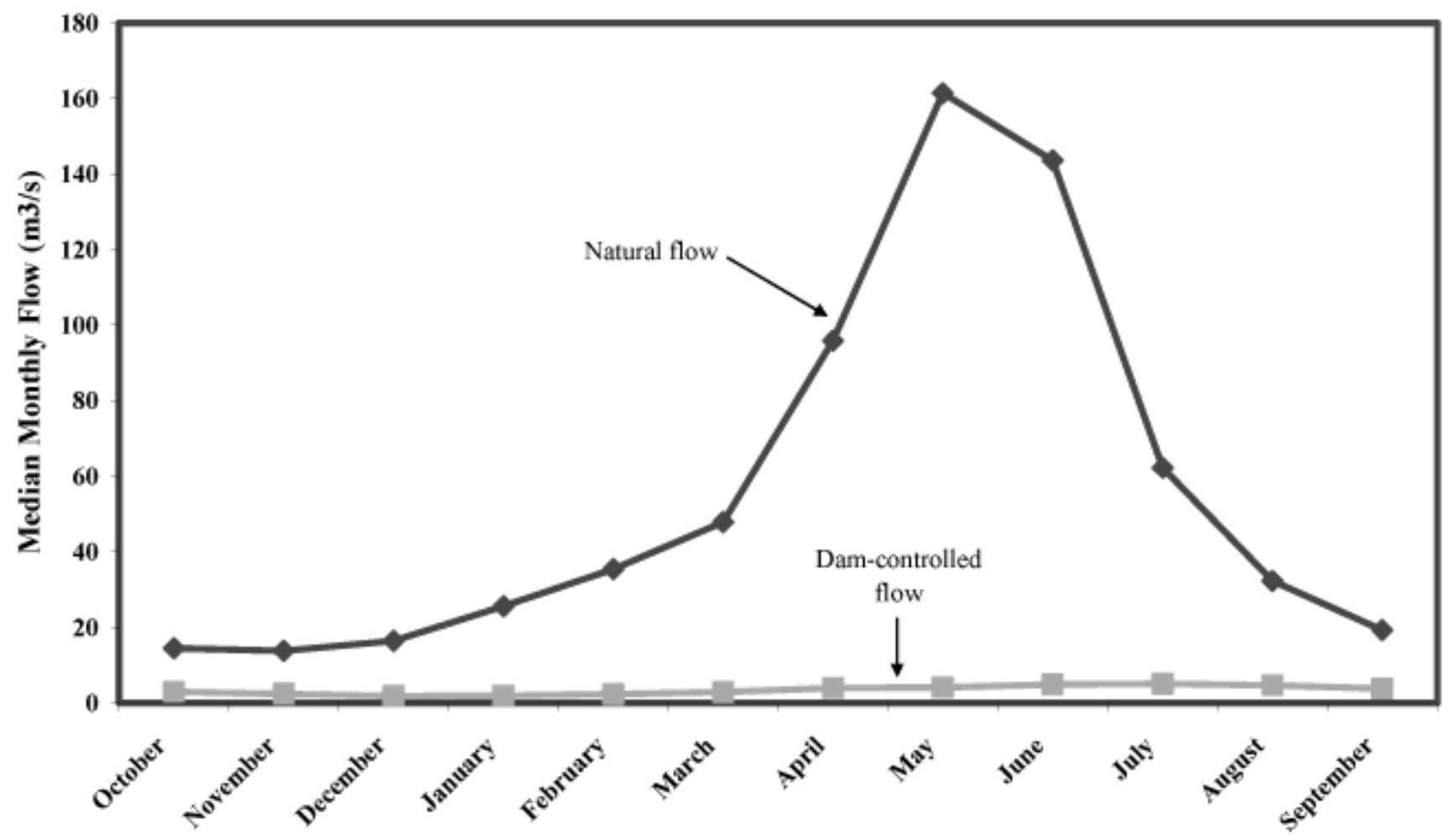

values, and other cultural or spiritual issues will need to be incorporated into the dam re-operation project. We believe that it is very important to educate, when necessary, and engage stakeholders in an open dialogue about the range of ecosystem services pertinent to the particular river under discussion. We have found it very useful to describe the various types of ecosystem services, i.e., "supporting," "provisioning," "regulating," and "cultural," as articulated in the recent Millennium Ecosystem Assessment (MEA 2005). Similar to ecological concerns, relevant social issues should be formulated into testable hypotheses to the extent possible that can be considered in the dam reoperation plan.

In all cases, formulating economic evaluations of the costs and benefits associated with any possible changes in dam operations will be of great value in planning the dam re-operation project. The practicality of re-operation ultimately reduces to a question of whether enough of the pre-dam ecological and social benefits can be restored to justify the costs, viewing both costs and benefits from the vantage point of full social accounting, not just an economic balance sheet. The economic subsidies required to make existing uses of dams viable are relevant to this assessment of the costs and benefits of re-operation. When irrigation or power generation subsidies, i.e., costs of current operations, are large and the benefits of environmental flows are appreciable, re-operation may be attractive from the standpoint of net social benefits. In the case of flood control dams, the costs and benefits of changing land uses in the floodplain to accommodate modest flood events might include the savings associated with disaster relief for settlers who were lured into a flood zone by dams that cannot, in fact, protect them from infrequent but severe runoff events. 
Fig. 4. Framework for planning and implementing a dam re-operation project.

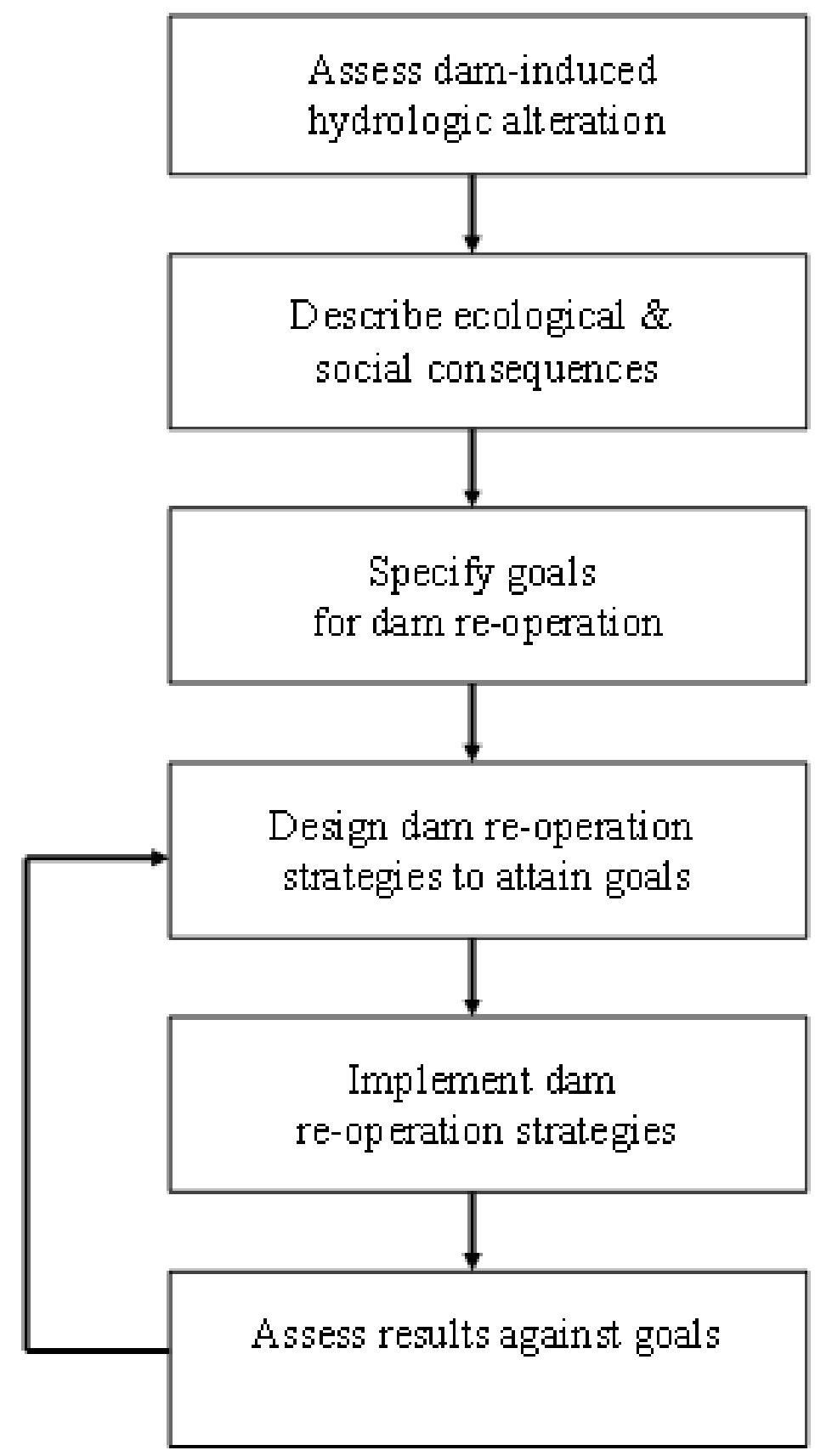




\section{Specify goals for dam re-operation}

The collective desire of stakeholders, resource managers, and dam managers for the outcome of the dam re-operation should be expressed as a set of goals. These goals are the byproduct of the social decision-making process described above, which results in conclusions about what benefits are "worth restoring" through dam re-operation. We strongly recommend that such goals define both the environmental and social conditions that, when achieved, would constitute success (Rogers and Bestbier 1997, Olsen et al. 2006). Too often, goals are stated so vaguely and broadly that it is difficult for anyone to disagree with them and they are of little use when assessing whether the re-operation project will contribute to achievement of the goals, or not. Defining goals as "sustainable development," "balance among competing activities," or "ecosystem health" may indicate the desired direction of change but little more. It is far more useful to set goals that define specifically how much and by when. For example, a recovery goal has been established under the U.S. Endangered Species Act for shortnose sturgeon under a fisheries plan for the Atlantic states that calls for establishing a minimum of at least 20-yr classes for females before reopening sturgeon fisheries on any river. This goal is helping to direct a dam re-operation project on the Savannah River in Georgia and South Carolina to create the specific river flow conditions necessary to support sturgeon and provide a target that can be used to evaluate whether the re-operation project is succeeding or failing.

In addition to defining goals with measurable target levels and specific dates for attainment, it is also important to define goals that can be achieved almost immediately. For instance, a primary problem with sturgeon in the Savannah River is that due to dam operations, adequate river flows have not been available during the period when sturgeon need to move upstream to their spawning grounds. The upstream movements of the sturgeon are now being monitored during dam releases designed to facilitate their access to the spawning grounds, revealing whether the modified dam releases are sufficient or not. Conclusive, short-term results can be very helpful in gaining public support for reoperation efforts.

\section{Design and implement dam re-operation strategies}

Later in this paper we provide considerable detail on potential strategies for modifying dam operations to attain new goals while continuing to provide most, if not all, of the original benefits for which the dam was built. Decision-support systems can be particularly useful in differentiating, prioritizing, and optimizing among multiple objectives for dam management (McCartney et al. 2005, personal communication). Dam re-operation strategies will need to be custom-tailored to achieve the specific goals adopted for the project. More specifically, it is essential to tailor the strategies to attain the specified levels and types of flow restoration necessary to realize the ecological and social goals. It is also important to acknowledge that even the most carefully designed re-operation strategies may need to be fine tuned, if pilot implementation and monitoring suggests the need to do so. In many instances, the physical character of the dam and its outlet works will constrain opportunities for flow restoration. For example, a hydropower dam's penstock may not have sufficient capacity to pass through the power generating turbines a "controlled flood" of sufficient magnitude to restore desired ecological processes downriver. Similarly, existing flood-control levees may prevent floodwaters from moving into floodplain areas targeted for restoration. As we discuss later in this paper, infrastructure modifications are commonly a necessary or desirable component of a dam reoperation project. The financial costs or social disruption, e.g., relocation of habitations higher up in the floodplain, necessary to restore flows to desired levels will need to be accounted for in the design of the re-operation project.

\section{Assess results against goals}

As emphasized previously, it is critically important to develop testable hypotheses linking river flows to ecological or social conditions, which are subsequently translated into well-defined goal statements. This provides the basis for assessing the success of the re-operation project. However, it is no small challenge to identify appropriate indicators of success (Rogers and Bestbier 1997, Richter et al. 2003). For certain goals, such as the sturgeon population goal suggested earlier, the appropriate indicator is obviously population abundance. However, it may be much more difficult to 
determine when adequate regeneration of floodplain trees or wetlands has been achieved, or when the desired level of utilization of the floodplain for pastoral grazing activity has been attained. The selection of the indicators to be measured, methods and frequency of data collection, and even the statistical approaches that will be used to assess relationships between river flows and indicator variables will require considerable forethought on the part of project designers (Richter et al. 2003).

\section{OVERVIEW OF STRATEGIES FOR RESTORING ENVIRONMENTAL FLOWS}

The operating purpose(s) of a given dam dictates the operating plan and the extent to which the dam stores and releases water on a schedule that distorts natural flows. The purposes of the dam will therefore also determine the types of techniques that can be applied to create the operational flexibility that can enable environmental flows to be restored as a permanent operational feature.

As a general rule, investigating opportunities for modifying dam operations will require a thorough assessment of not only the operating rules that govern the day-to-day operations of any specific dam, but also the physical mechanisms by which the benefits, i.e., water, energy, from the dam are distributed, the end uses of those benefits, and the socio-political and economic drivers that ultimately dictate dam operations. For instance, re-operation of an agricultural water supply dam may require assessment of the entire irrigation system, with an eye toward changing water use behaviors that are ultimately causing the undesired alteration of the natural flow regime. In cases in which hydropower operations are responsible for the flow alterations, an assessment of the entire energy grid that includes the dam along with many other energy sources may be necessary. When the driver is flood management, strategies to accommodate larger controlled flood events in the downstream floodplain may be required. Therefore, our discussion of opportunities for restoring natural flows will focus on the modification of "systems" instead of only dams.

\section{Modifying flood management systems}

Flood control facilities can be re-operated to permit seasonal inundation of floodplains for environmental and floodplain production benefits, e.g., fisheries, grazing, flood-recession, agriculture, and timber production, if conflicts with existing downstream land uses can be ameliorated. A primary reoperation goal for flood control facilities consists of creating conditions under which a larger fraction of flood events can be allowed to pass through the dam into the downstream floodplain. Below we discuss some options for selective reconnection of floodplain areas for flood storage purposes. By restoring floodplain storage capacity, facilities designed to control a 20-yr flood event might be reoperated to only control the 50-yr and higher flood events. The physical structure of a dam's outlet works and spillway can be a serious limiting factor on many flood-control dams, particularly when necessary structural modifications to enable higher flood releases are prohibitively expensive. Many flood control dams include both an outlet pipe and a spillway. Commonly, the capacity of the outlet pipe is too small to pass floods of the desired magnitude, and dam managers may be reluctant to allow water to overtop the spillway due to structural or other concerns. This creates a situation in which the outlet pipe can only release the equivalent of a high-flow pulse, e.g., less than the 2-yr flood, and only the most extreme large floods overtop the spillway, thus eliminating all small- to mediumsized floods. Structural modification is required in these situations to allow more flexibility in releasing higher-magnitude events in controlled fashion.

Oftentimes, the modification that is necessary to permit more natural flooding patterns is to reduce the consequences of periodic inundation in the downstream floodplain. If the land use constraint is immutable, such as the presence of extensive human settlements, expensive structures such as roads or bridges, or permanent high-value crops such as orchards, it may be that increased inundation of the floodplain is simply not feasible. In other cases, the land use constraint may be amenable to relocation of low-value structures, seasonal flood easements over farmlands that grow annual crops, or construction of embankments to prevent inundation of high-value areas. In these situations, re-operation to improve the ecological functionality of the downstream floodplain may indeed be feasible. 
In considering the social values associated with flood restoration, it is important to note that reestablishing a floodplain inundation regime can make both the floodplain and the river more productive for a variety of user groups. The resultant enhancement of fish and wildlife populations can improve food availability, and many cultural groups use fiber from floodplain reeds or trees for building materials and other purposes. Improved wildlife viewing opportunities can be extremely beneficial to local tourism economies. It can also benefit agriculture on the floodplain through the regular deposition of nutrients, flushing of soil salinity, and the recharge of groundwater aquifers. Although some dwellings may need to be relocated to higher ground to make flood restoration possible, this is not like the resettlement problems associated with new dam construction and reservoir inundation, which reduces river and floodplain productivity. Here we highlight some strategies that can create flexibility in flood management systems.

\section{Flood routing and storage in retention basins}

Floodwaters can be allowed to fill natural depressions on the floodplain during periods of high flow. Floodwater may flow onto the land during periods of high river flows and then exit through the same route as the river stage lowers. In some cases, such temporary flooding has been controlled through engineered floodgate structures built into levees that allow water to move into the floodplain for a limited period, and then subsequently discharge back into the river as water levels drop in the river channel. Another possibility is that the excess flow will travel down the river valley in a "bypass" and re-enter the river some distance downstream, effectively increasing the flood conveyance capacity during periods of high flow. This can provide some degree of flood restoration benefit, while also providing flood storage to reduce damages downstream. Possible added benefits include transport of sediment and nutrients to agricultural lands, replenishment of floodplain aquifers, and revitalization of wetlands. The main trade-off associated with this management strategy is the loss of the use of the land during inundation.

This technique often requires some accommodation by landowners or other users of the affected areas, such as through flood easements, purchase of the land for parkland, or some other form of compensation for any lost utilization of the land or resources, e.g., subsistence floodplain farming or grazing. Flood easements are agreements with landowners that allow flooding of privately held lands for a limited time. One tradeoff associated with this strategy can be a delay in planting crops during the inundation period, which may be offset to some degree by the increased moisture and fertility of the soil during the remainder of the cropping season or in subsequent years. The negative side-effects of flooding can be addressed by purchasing flood easements or purchasing the land for nature preserves or other uses that are compatible with occasional flooding, or negotiating management agreements or compensation with owners of communal lands.

\section{Levee setback}

Levees built along a river can severely limit or prohibit a river from interacting with its floodplain. By moving levees further from the river channel, a river can flood onto a broader expanse of its floodplain. This provides benefits both in terms of flood control and ecosystem restoration. The further the levees are set back from the river, the greater the increase in flood storage and flood-related ecosystem benefits. These ecosystem benefits can include the partial or full restoration of fluvial geomorphic processes such as river meandering or bar formation that benefit aquatic species and riparian vegetation. The main tradeoff associated with this strategy is seasonal loss of the use of the land located riverside of the new levee system. Agriculture may still be possible within the levees; however, the natural movement of the river, and associated erosion and sediment deposition, may disrupt these operations.

\section{Case study: restoring high flows on the Savannah River}

The U.S. Army Corps of Engineers operates three large multipurpose dams on the Savannah River, which forms the border between the states of Georgia and South Carolina. The furthest downstream is Thurmond Dam, constructed in 1954, which is operated primarily for flood control. A dam re-operation project focusing on Thurmond Dam was initiated under a partnership in 2002 between the Corps of Engineers and The Nature Conservancy, an international conservation organization, with legal services provided by the Natural Heritage Institute, a nonprofit environmental law firm. 
An assessment of the hydrologic alteration associated with the dam revealed significant changes in virtually all aspects of the flow regime, particularly in higher flow events (Richter et al. 2006). Thurmond Dam has been quite effective in controlling floods and high-flow pulses (Fig. 5). Small and large floods have been eliminated, and high-flow pulses greater than $450 \mathrm{~m}^{3} / \mathrm{s}$ occur with less frequency, particularly since 1980 . However, annual average discharge has been reduced by only $15 \%$ due to water extractions, from 308 to $263 \mathrm{~m}^{3} /$ $\mathrm{s}$.

The Corps of Engineers began conducting a stakeholder input process in 2003, whereas The Nature Conservancy engaged more than 50 regional scientists in an evaluation of the ecological implications of flow alteration in the river, floodplain, and estuarine systems (Richter et al. 2006). These scientists generated a comprehensive environmental flow recommendation, including specifications for both high-flow pulses and small floods (Fig. 6). The ecological goals represented in Fig. 6 can be viewed as hypotheses to be tested in the dam re-operation project.

The attainment of small flood restoration on the Savannah faces some substantial obstacles. Prior to dam construction, small floods ranged from 2500 to nearly $6000 \mathrm{~m}^{3} / \mathrm{s}$. However, considerable floodplain development has taken place since dam construction. Various structures such as an outdoor amphitheater in the city of Augusta, Georgia would begin to be inundated at $1000 \mathrm{~m}^{3} / \mathrm{s}$, and recently constructed houses would be flooded at flows of $1500 \mathrm{~m}^{3} / \mathrm{s}$. One option that has been proposed is to construct a flood bypass around the city, so that higher flows could be safely passed into the lower reaches of the river.

In the meantime, the Corps has begun releasing high-flow pulses ranging from 450 to $850 \mathrm{~m}^{3} / \mathrm{s}$ to benefit fish spawning and access to low-lying floodplain areas, flush oxbow lakes, and disperse the seeds of floodplain trees. The Corps achieves this by allowing water levels in the reservoir to rise slightly to about $0.5 \mathrm{~m}$ above their normal target level, i.e., rule curve, for flood control operations. National Corps policy for flood control operations allows for temporary, minor encroachments of a reservoir's "flood pool." When the Corps is ready to release a high-flow pulse for environmental flow benefits, the reservoir level is allowed to rise in the weeks preceding the planned release, providing adequate water volume to create the high-flow pulse. This case study illustrates the fact that certain aspects of environmental flow restoration can be accomplished with little to no infringement on other existing water uses or dam purposes.

Species of concern such as short-nosed sturgeon (Acipenser brevirostrum) and floodplain tree recruitment are being carefully monitored as part of the adaptive flow restoration program on the Savannah (Richter et al. 2006), and monitoring results continue to inform the dam re-operation project (per Fig. 4). For example, the results from initial high-flow pulse releases to facilitate sturgeon migrations to their spawning grounds suggested that water temperature would likely also have an influence when the sturgeon migrate; recent releases have been timed to coincide with appropriate water temperature.

\section{Modifying hydropower systems}

Hydropower reservoirs store water to create hydraulic "head" for power production either at the dam or at some point downstream. Some of these facilities operate, more or less, on a run-of-the-river mode, when the reservoir is used simply to create the hydraulic head without storing a significant volume of water. Generally, these are facilities in which the capacity of the reservoir is small relative to the annual flow of the river. However, most hydropower reservoirs store and release water on a pattern to generate power during times of highest electricity demand, i.e., peak power facilities. Electrical demands generally peak during particular times of day when, for instance, lights are turned on in the evening or air conditioners are turned on in the late afternoon when workers return home, and during particular seasons, such as summer for cooling or winter for heating. In some cases, water may be captured in a storage reservoir and held for months before being used for power generation. The resultant dam releases can be completely out of phase with natural flow patterns, resulting in considerable damage to downstream river ecosystems and associated species, as well as livelihoods associated with aquatic or floodplain resources. If hydropower dams can be operated to release water on a daily basis at a rate that is closer to the rate of natural inflow into the reservoir, impacts on downstream ecosystems can be reduced. The primary obstacles to this type of dam reoperation include the potential revenue losses 
Fig. 5. Annual floods have been substantially lessened on the Savannah River since the construction of Thurmond Dam in 1954.

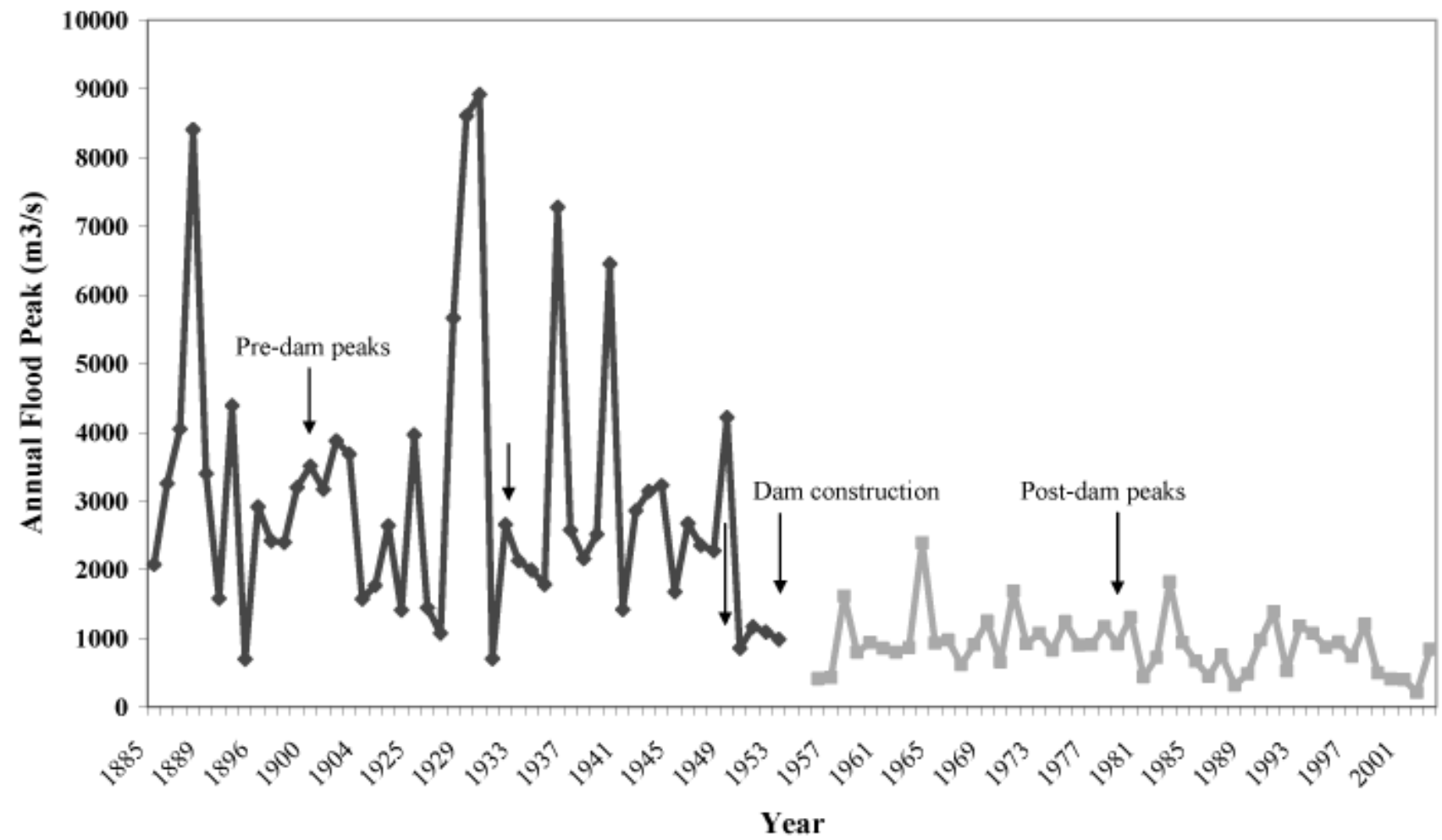

associated with displacement of power production to times of lower economic value. Here we highlight some strategies that can minimize or offset these losses.

\section{Re-regulation reservoirs downstream of hydroelectric} dams

The hydrologic impacts of hydropower generation can be mitigated by either constructing a "reregulating" dam, usually built immediately downstream of the hydropower facility, or by using one or more of the lowermost dams in a cascade to re-regulate the flow alterations caused by upstream dams. A re-regulating dam can be operated to "undo" the unnatural fluctuations caused by hydropower operations on a day-to-day or withinday basis, releasing water in a pattern much closer to natural flows. The ability of a re-regulating dam to restore natural flow patterns will depend upon the extent to which the upstream hydropower dam has altered them; essentially the same volume of storage capacity is needed to both alter flows at the hydropower dam and to restore flows at the reregulating dam. However, because regulating dams usually only reshape daily releases, their capacity is typically quite small and therefore their cost is usually a small fraction of the cost of the hydropower dam. Additionally, the re-regulating dam can be fitted with generators that can "returbine" the water and generate compensating revenues.

\section{Pumped storage facilities}

In a pumped storage system, water is pumped from the hydropower reservoir into an offstream storage reservoir at a higher elevation during off-peak demand periods and released back to the hydropower reservoir during times of peak demand. 
Fig. 6. The ecological goals for a dam re-operation project on the Savannah River in the southeastern United States are summarized in this diagram. Specific ecological outcomes are noted in each box, which is linked to particular levels and durations of water release from the dam during specified times of the year, or during various water year types, e.g., wet, average, dry. Many of the ecological goals represented in this diagram were championed by economic or social interests, such as commercial fishing (adapted fom Richter et al. 2006).

\section{Environmental Flow Recommendations}

\section{Savannah River below Thurmond Dam}

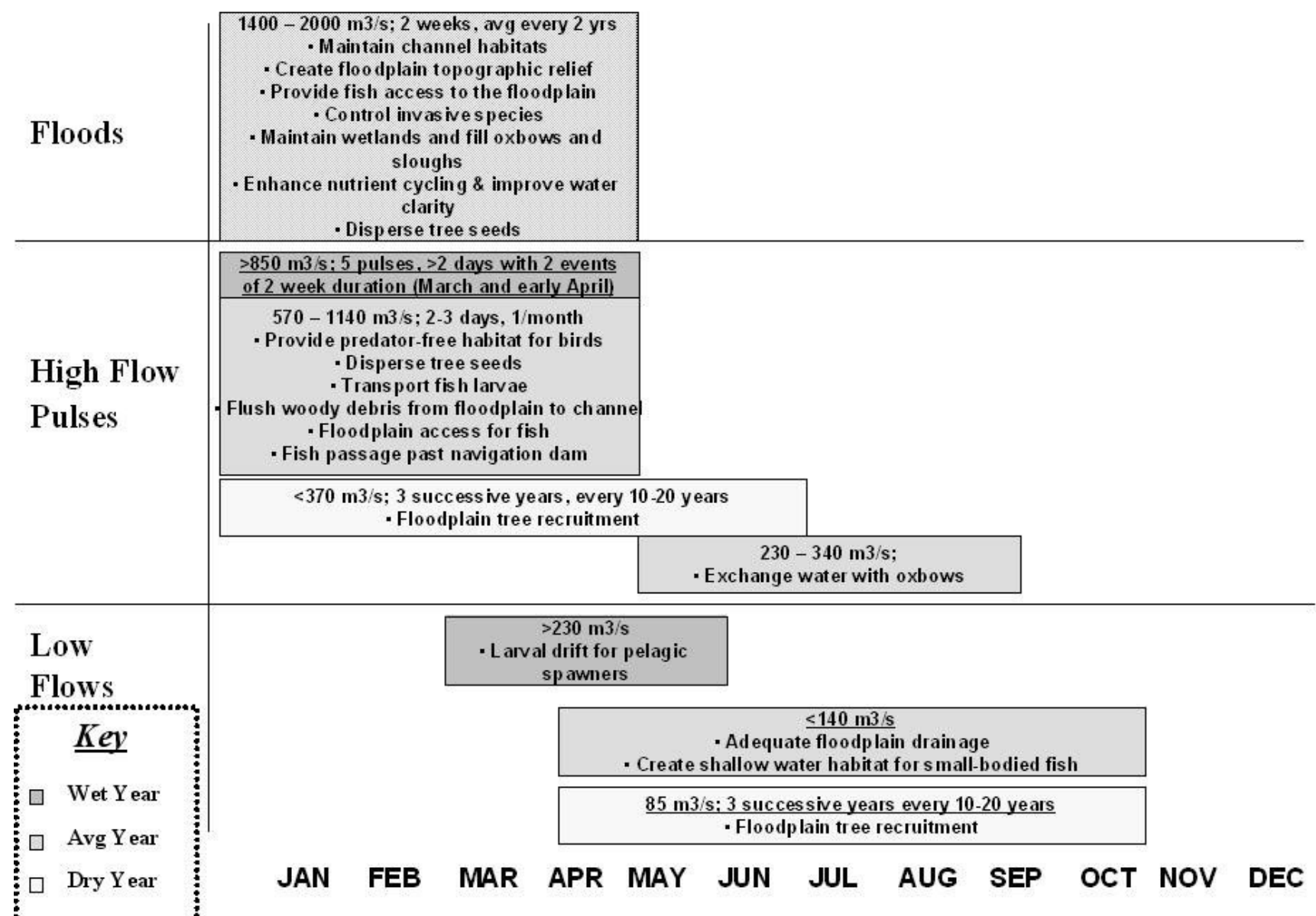

The pumped storage reservoir also generates power when it releases water. Although the technique costs more power than it returns, it is used to maximize peak power production, resulting in greater power generation revenues. Usually, the hydropower dam generates power during the day when electricity demands and energy values are greatest, and water is pumped back during the night when energy demands and pumping costs are lower. By incorporating pumped storage capabilities, a hydropower system can often generate the same amount of energy with considerably less storage capacity. Because less water needs to be stored in reservoirs, much of the natural inflows to the 
hydropower reservoir can be passed downstream, thereby moderating impacts on natural flow patterns.

\section{Substitution of hydropower peaking facilities}

When more than one hydropower dam exists on a river, or on multiple rivers, opportunities for modifying the function of any one dam will likely be increased considerably. In many rivers around the world, "cascades" of hydropower dams have been constructed. In a cascade of closely stacked reservoirs with little flowing water in-between, the ecological health and ecosystem services provided by upstream dams may have already been so compromised that it would do little additional harm to generate more power at the upper dams. Oftentimes the operations of these cascades is not fully integrated or optimized for either hydropower generation or environmental flow performance. This may be due to the fact that more than one entity owns the dams in the cascade, or the computational skills or technologies necessary to achieve a high level of optimization have not been used. In these systems, it may often be possible to re-operate any large storage dam(s) that control flows, but not necessarily the most downstream dam, into a formerly productive downstream floodplain for environmental performance, and then also reoperate the other dams in the cascade to compensate for the loss of peak power production by the present environmental flow reservoir, without loss of power revenues. In this manner, energy generation can be maximized at upstream dams to enable lower dams to serve more of a re-regulating function, thereby minimizing flow alterations in the downstream river.

Similarly, when dams are located on more than one river but supplying power to the same location(s), energy generation and environmental flow impacts can either be balanced among multiple dams or impacts can be "traded off" to provide more flow restoration to highest priority rivers. This strategy reaches its greatest potential when many hydropower dams are feeding into the same energy grid system. If the grid system is geographically expansive, it is quite likely that climatic differences exist across the grid at any given time, or rivers of different sizes are being used for hydropower generation. These differing climatic conditions and river sizes make it quite likely that water available for generating hydropower will differ considerably across the grid. To the extent that power generation can be optimally aligned with that natural water availability, prospects for environmental flow restoration can be maximized, although it may entail increased complexity in addressing a broader range of stakeholder interests. Investment in a computerbased decision support system is one of the most cost-effective ways to optimize the performance of a multi-dam hydropower system. When environmental flow criteria such as minimizing departures from the natural flow regime are included in the optimization scheme, the considerable flexibility in a multi-dam operation can be effectively tapped for environmental flow restoration.

\section{Energy grid optimization}

The strategy described above, in which power generation is optimized across an electrical grid system, can be taken even further by optimizing power generation across all contributing energy sources: hydropower, coal, nuclear, natural gas and petroleum, biomass, wind, and solar. The major challenge here is to investigate ways in which the role of one or more hydropower dams in the mix of energy generators feeding the grid can be changed to allow the hydropower dam(s) to supply "base load" electricity, i.e., run-of-the-river operations, instead of "peak load," and to use differences in water availability across many river basins to "fill in" peaking power needs as described above.

\section{Hydrologic forecasting}

Hydrologic forecasts used in hydropower operations are typically based on a combination of weather forecasts and direct measurements of reservoir levels, precipitation, river flows, and snow conditions in the catchment. By using a decision support system that includes hydrologic simulation and reservoir operations modeling, with hydrologic forecasts as inputs, a hydropower operator's ability to meet both energy demands and environmental flow objectives can be increased greatly (McCartney et al. 2005, personal communication). Furthermore, hydrologic forecasts can often be improved substantially by installing additional climate and water monitoring instruments in the catchment. 


\section{Case study: reducing hydropower impacts on the Roanoke River}

Two private hydropower dams have been impacting fisheries and an extensive floodplain forest along the lower Roanoke River in North Carolina since they began operations in 1955 and 1963. During each growing season, young tree seedlings sprout on the forest floor, but each year, the young trees are inundated and killed by prolonged, artificial high-pulse flows resulting from power generation episodes. An agreement was reached with the hydropower utility company to reduce the frequency of these unnatural pulses during the growing season. Perhaps more importantly, the span of time between pulses is to be increased, so that floodplain soils have sufficient time to dry out and re-oxygenate, a critical factor in reducing tree mortality. The utility company agreed to this dam re-operation plan because it is able to make up the lost power through other hydropower dam operations within its system, and because the financial consequences for its investors were negligible (Pearsall et al. 2005).

The flow restoration story on the Roanoke continues, however, because natural flooding regimes have also been impacted by a Corps of Engineers flood-control dam located upstream of the private hydropower dams (Fig. 2). Discussions are now underway to restore small floods $(\sim 1000$ $\mathrm{m}^{3} / \mathrm{s}$ ) to the river by changing the operating rules for flood control. The possibility of restoring a more natural level of flooding has been greatly enhanced by the purchase of most of the affected floodplain lands downstream of the dams by conservation interests.

\section{Modifying irrigation supply systems}

Water supply reservoirs for irrigation constitute half of the world's large dams, with the largest number in China, India, Pakistan, and the United States (WCD 2000). These dams generally provide both seasonal storage and interannual storage of water to buffer the variations in natural runoff and provide a reliable supply of irrigation water. Most irrigation reservoirs capture water throughout the year, oftentimes releasing very little or no water to downstream ecosystems except during extreme flood events. A basic goal in re-operating an irrigation supply reservoir is to avoid capturing water during low-flow periods, and instead maintaining reservoir storage by shaving higher flow events. However, in some cases the volume of high flows being captured during the wet season and subsequently released during the dry season for irrigation are so large that it becomes very difficult to reshape the hydrograph to a more natural seasonal pattern. There are a variety of techniques for changing the management of irrigation supply systems in ways that increase flexibility in storage and release, some of which we discuss below. Before discussing ways to modify the operation of irrigation supply reservoirs, however, we want to emphasize that the best way to open up flexibility in infrastructure operations in agricultural settings is to reduce the overall demand for water in the first place.

\section{Gaining "more crop per drop”}

Because agriculture is by far the single largest consumptive user of water (UNEP/GRID-Arendal 2002), strategies for reducing physical losses in agriculture can create significant opportunities for environmental flow restoration in rivers that have been excessively depleted. In agriculture, water moves in four directions, and by tracking its fate we can understand where losses can be harvested to supplement environmental flow needs: (1) irrigation water can flow upward into the atmosphere where it is lost to evaporation; (2) it can flow downward where it may replenish groundwater that is being beneficially used, or it may percolate into deep or saline aquifers and be lost to subsequent reuse; (3) it can flow inward, that is, into the biomass that is the product of agriculture; or (4) it can flow outward, as water flows from agricultural lands back into rivers or streams. The first three routes, i.e., up, down, and in, each present opportunity for the application of improved technologies and techniques. Evaporation, i.e., the upward flow, can be reduced through improved methods of applying irrigation water. The downward flow can be reduced through application of proper amounts of water. The inward flow into biomass can be reduced by replacing existing crops with high value, water frugal crop types. Of course, all of these losses of water are curtailed when agricultural land is fallowed, as in dry-year leasing arrangements.

\section{Relocating points of diversion and return flow}

Points of diversion of irrigation water can sometimes be relocated downstream of the existing outtake, thereby shortening the length of river 
subject to flow alteration (Molden et al. 2004). When the storage and release regime of the irrigation water supply dam can also be modified to re-introduce high flow events through this same reach, more natural flow conditions can be reintroduced through a longer reach of the downstream floodplain. This technique can be particularly useful if the new diversion point is located downstream of an unregulated tributary. The tradeoff associated with this shift may be the required use of pumping at the new diversion point, because relocating the diversion downstream results in a reduction in its elevation and may therefore prevent water delivery by gravity flow alone.

\section{Integrating groundwater and surface storage: conjunctive water management}

In many areas of the world, irrigation projects have been built to counteract historical groundwater depletion, which has made irrigation infeasible due to increased costs of pumping water from greater depths. In these situations, "conjunctive management" of surface and groundwater supplies will likely be a promising strategy (FAO 1995, Pillai 1999). Conjunctive water management in this context consists of coordinated operations of a water supply reservoir and a groundwater system usually located downstream of the dam. The goal of dam reoperation in this instance is to expand the amount of storage available for irrigation supply by enhancing groundwater recharge using surface water from the water supply reservoir. The recharge can take place on the river floodplain using managed flood inundation, or canals can be used to convey water to a recharge pond. In lieu, recharge can be used wherein areas pumping groundwater are furnished a substitute surface water supply from the reservoir, allowing natural recharge to replenish the groundwater basin during the storage phase, and groundwater can be pumped instead of surface water deliveries during the extraction phase. To avoid further alteration of low-flow conditions, the water used for enhanced groundwater recharge should be captured in the irrigation supply reservoir only during higher flow events. The increased reservoir storage gained by use of enhanced groundwater recharge can open up considerable opportunity for environmental flow restoration. With elevated or restored groundwater levels downstream of the dam, more-natural base-flow conditions may be restored through improved discharge of groundwater to the river channel. Additionally, the storage capacity previously used in the water supply reservoir for irrigation purposes may become available for controlled releases of low flows, high-flow pulses, or even small floods.

\section{Case study: restoring environmental flows in the Central Valley of California}

This case example features theoretical work, rather than empirical results, that confirms the potential for optimizing irrigation water storage systems to achieve three objectives simultaneously: (1) augmentation of irrigation supply, (2) improved flood management, and (3) restoration of more natural flow patterns in the river downstream of the reservoir. Detailed modeling of the Central Valley water system in California shows, at a proof-ofconcept level of detail, that the technique should be broadly applicable in irrigation systems around the world that have the requisite physical, economic, and legal and institutional attributes.

The physical conditions necessary to implement this conjunctive water management technique are illustrated by the Central Valley:

- The existence of a large irrigation storage reservoir relative to the annual flow of the river that controls flows into a formerly productive floodplain, wetlands system, delta, or estuary;

- The existence of an aquifer, either underlying the irrigated area or nearby, that has the appropriate geological conditions, soil conditions, and water quality to serve as a water bank.

When these conditions exist, and they are common to many irrigation systems, the mechanics of the technique works as follows. A fraction of the water that remains in the reservoir after the irrigation season but before the refill season is conveyed to groundwater recharge facilities, i.e., in the case of active recharge, to be used for irrigation the following growing season. Alternatively, irrigation demands that would have been met by using groundwater are now instead met by further depleting the surface reservoir. This results in increased storage availability in the reservoir following the irrigation season. During the postirrigation wet season, this new reservoir storage capacity is filled by shaving floods and high-flow pulses, while continuing to release water in a near- 
natural pattern from the reservoir. The "new water" now being stored can be released from the reservoir throughout the year in a pattern that more closely mirrors natural flow variability.

In many irrigation systems, water is released from upstream reservoirs during the irrigation season to supply water to farms. Because these reservoir releases are commonly made during the dry season, the releases result in artificial enhancement of the natural low flows in the river, to the detriment of native species that may have relied on low-flow conditions for various biological reasons. By using enhanced groundwater storage, if available, during the irrigation season instead of water released from an upstream reservoir, this problem of artificially elevated low flows can be ameliorated.

Modeling of conjunctive uses of surface and groundwater in the Central Valley of California, with eleven large reservoirs that feed into the valley, shows that an average of approximately $1230 \mathrm{~m}^{3} / \mathrm{yr}$ can be generated for use in environmental flow restoration, and/or for additional water supply, at a cost less than the marginal cost of water supply in the system (Purkey et al. 1999). This is enough water to substantially restore natural flow patterns in all eleven of the regulated tributaries. The constraint on doing so is not a limit on the ability of the reservoirs to generate the environmental water but rather limits on the ability of the downstream floodplains to accommodate these environmental flows in view of the land use and structural encroachments that have been induced by the previous pattern of flow regulation. The degrees to which these physical and economic constraints can be ameliorated are the focus of a next phase of analysis. Although we have referred to the reservoir water to be used for environmental flow restoration as "new water," we acknowledge that this water is gained only by reducing flood flows, which may appear inconsistent with holistic environmental flow restoration. Essentially, the techniques proposed here seek to convert some portion of the floodwaters into controlled inundations explicitly for, and in a manner tailored to achieve, prespecified environmental restoration objectives. We are, in effect, using hydraulic infrastructure intentionally for environmental water management.

\section{Modifying urban water supply systems}

The challenge of meeting urban water supply demands is expected to intensify considerably during coming decades as a product of two global megatrends (Fitzhugh and Richter 2004). The global population is expected to increase from around 6 to $9 \times 10^{9}$ by 2030 . During that same period, the percentage of the population living in cities is expected to increase from $47 \%$ to $60 \%$ (UN 2003). These trends suggest that stresses on freshwater systems proximate to urban areas will grow if environmental flow needs are not adequately addressed in urban water supply plans.

Some of the strategies discussed previously for modifying irrigation supply systems, such as relocating points of water diversion downstream and even conjunctive management of surface and groundwater, are equally applicable to urban water supply systems. Here we will emphasize aspects of urban supply systems that differ substantially from irrigation supply systems to provide some specific recommendations that can be used by urban water managers. In general, urban water supply reservoirs tend to be of smaller size than irrigation reservoirs, which usually translates into lower potential impact on natural flow regimes. Many on-channel urban reservoirs fill quickly during runoff events and spill the excess inflow, thereby preserving natural flow patterns to a large extent. However, many urban reservoirs are capable of substantially altering flow regimes. The following approaches can help to mitigate their impacts.

\section{Demand management}

Many cost-effective methods for water conservation in cities already exist, and new technologies are constantly evolving that will enable even greater efficiencies (Gleick 2000, Vickers 2001, Gleick et al. 2003). A recent study in California found that $30 \%$ of urban water use could be saved using existing technologies at costs below what it would cost to tap into new sources of supply (Gleick et al. 2003). In many cities with aging infrastructure, significant opportunities may exist to reduce leakage in the water supply distribution system (Vickers 2001). By lowering overall urban demand, less storage is needed and the potential for alteration of natural flow variability is lessened. Furthermore, by reducing demand, water conservation measures can reduce the amount of water that needs to be extracted from rivers. 


\section{Drought management planning}

Most urban water supply reservoirs are designed to provide a "safe yield" of water during an extreme drought, meaning that the reservoirs are designed to not run dry during droughts. Commonly, the drought of record is used as the basis for designing urban reservoir capacity. This has two important implications for environmental flow protection or restoration. First, it means that considerable flexibility usually exists in "normal" to "wet" years to provide natural-like flow releases from urban reservoirs because water managers are at little risk of depleting available water storage. Second, a carefully designed suite of water conservation measures, such as lawn-watering restrictions or temporarily elevated pricing structures, can be implemented during droughts to substantially lessen demand, thereby requiring less reservoir storage and creating more opportunity for meeting environmental flow needs, which should approximate naturally low-flow conditions during droughts.

\section{High-flow skimming}

From the perspective of environmental flow protection, it is generally preferable to extract water for human uses during naturally high water periods rather than during low-flow conditions whenever feasible. However, such "high-flow skimming" requires use of a reservoir to store water for later use during drier periods. In addition, the storage capacity of the reservoir must be adequately sized to prevent the need to capture water during low-flow periods. If the extracted water is to be stored in an off-channel reservoir, the diversion intake must be sized large enough to facilitate high rates of water extraction during high-flow events. These highflow extractions should be guided and limited by environmental flow targets designed to maintain necessary ecosystem functions during these highflow periods.

\section{Use of off-channel reservoirs}

When a storage reservoir is built off-channel, it greatly reduces the potential ecological impacts due to the avoidance of sediment and nutrient entrapment, blockage of fish passage, and temperature alterations. This strategy is best used in conjunction with high-flow skimming to fill the reservoir during high-flow events. In some settings, existing ponds, quarries, and other depressions can be put into temporary service during droughts, thereby reducing the storage needed in primary supply reservoirs to ensure safe yield during droughts. In the Peace River basin in Florida, pumping of water from abandoned limestone quarries is used to supplement low flows in the river that would otherwise be excessively depleted by groundwater pumping for urban water use.

\section{Forecasting}

The traditional approach to managing an urban water supply reservoir is to maintain a full reservoir at all times. Therefore, any storage lost during dry times of the year or during droughts is refilled as soon as additional inflow is available. This commonly causes severe reduction, and even complete curtailment, of environmental flow releases from the reservoir during the refill period. Reservoir managers may be reluctant to release water out of storage for environmental flow purposes during low-flow periods unless they have some confidence that the reservoir will soon be refilled by a higher flow event. Forecasting can provide reservoir managers with greatly increased capability for dealing with the risks associated with releasing environmental flows. Numerous forecasting strategies are available, including sophisticated climate models and rainfall-runoff simulations. A simple probabilistic approach can be applied when reasonably long-term historic records of streamflow in the river basin are available. This approach is based upon plotting the historic cumulative inflow volume curves for each year of record (Fig. 7), with all curves beginning at the day of year on which the forecast is to be made. A reservoir manager can use these curves to estimate the likely probability that inflow volumes will be sufficient to maintain the reservoir at a target level, e.g., never dropping lower than $20 \%$ of capacity, while continuing to make environmental flow releases. In the absence of historic streamflow records, hydrologic simulation models can be developed and used to synthesize a time series of streamflow from which probabilistic forecasts can be derived.

\section{Case study: meeting 50-yr water supply demands and ecosystem needs on the Rivanna River}

The Rivanna River basin is a water source for more than 90,000 residents of the city of Charlottesville and Albemarle County in central Virginia. 
Fig. 7. This graph of cumulative water availability beginning 1 May illustrates the likelihood of differing volumes of water becoming available during summer months under wet-, average-, and dryyear conditions for the Rivanna River in Virginia, USA. Estimates of water availability have been used to develop forecasts for meeting growing urban water demands whereas releasing environmental flows from storage reservoirs in the Rivanna Water and Sewer Authority's water supply system in Charlottesville, Virginia.

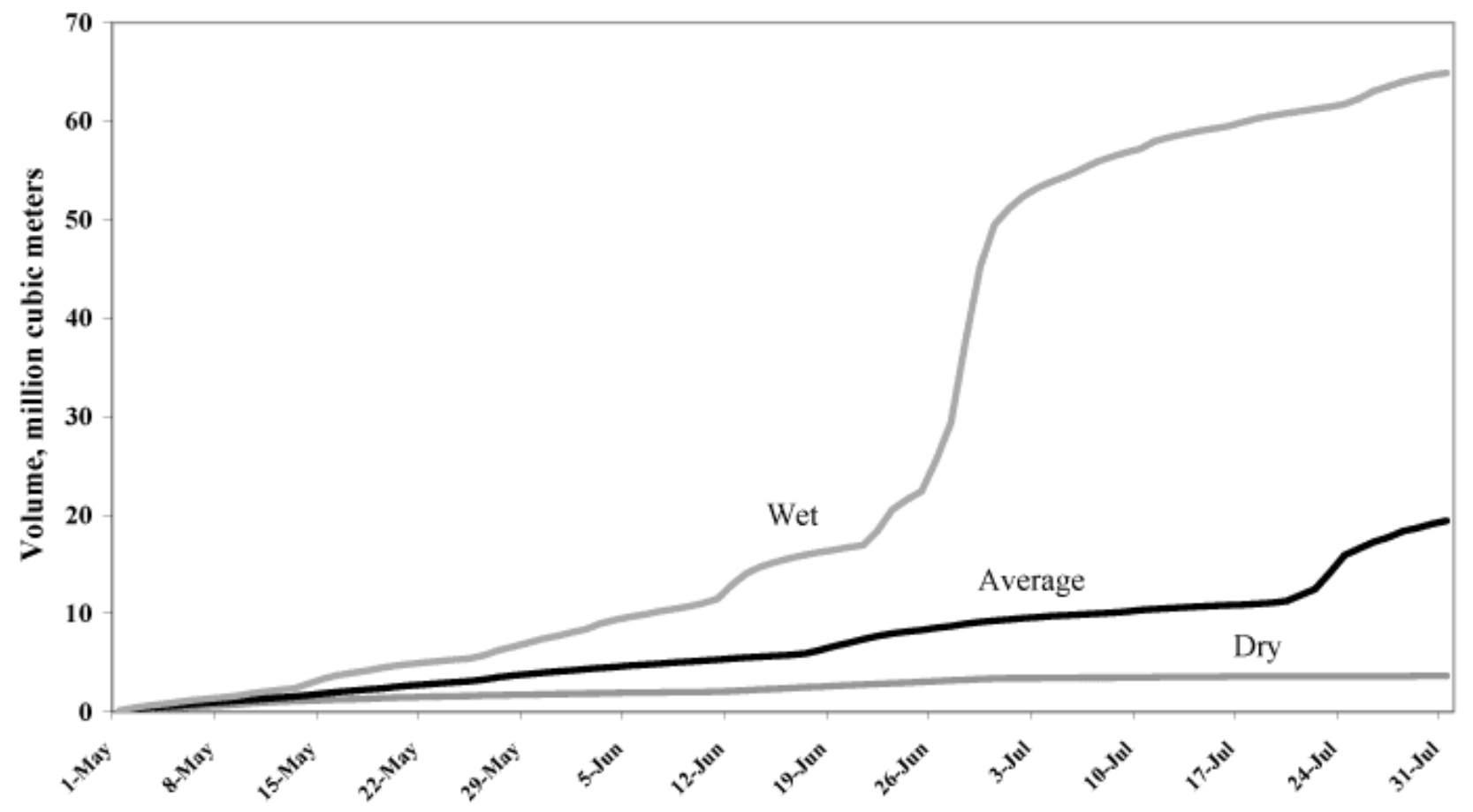

Day of Year

Following a drought of record that ended in 2002, the Rivanna Water and Sewage Authority (RWSA) began developing a 50-yr water supply plan intended to meet the area's rapidly growing water demands. Environmental interests advocated strongly for protection of the river's ecological health, which supports important recreational pursuits such as fishing and canoeing. Three primary reservoirs are presently used for RWSA's water supply system, which produces $44,300 \mathrm{~m}^{3} / \mathrm{d}$. One is located on the South Fork of the Rivanna River, one on a tributary to the South Fork of Moormans River, and the third is an off-channel reservoir. Environmental flow releases have historically been set at a constant release rate of 0.34 $\mathrm{m}^{3} / \mathrm{s}$ from the South Fork Reservoir, and $0.002 \mathrm{~m}^{3}$ / $\mathrm{s}$ from the reservoir on the Moormans.
Three strategies will be used to meet a projected water demand of $69,290 \mathrm{~m}^{3} / \mathrm{d}$, a $56 \%$ increase by the year 2055. First, the capacity of the off-channel reservoir will be increased in capacity by $7.8 \times 10^{6}$ $\mathrm{m}^{3}$. This enlarged reservoir will be filled primarily by skimming high flow events in the South Fork Rivanna River. Second, a three-stage drought management plan, including a voluntary phase followed by two mandatory phases of increasing demand restriction, will be implemented, minimizing the necessary expansion of the offchannel reservoir by reducing water demands during drought periods. Third, a probabilistic forecasting strategy is used to identify periods in which the drought management plan will need to be triggered to conserve storage in the reservoirs while continuing to provide releases for environmental flows. 
Under the new water supply plan, environmental flow releases from South Fork Reservoir will range from $70-100 \%$ of natural inflow at least $90 \%$ of the time, dropping to $30-50 \%$ of natural inflow only during extreme droughts. These environmental flow releases will substantially restore natural flow variability, as compared to the static environmental flow releases provided historically. The variable flow release targets were developed through an environmental flow needs assessment involving more than 40 scientists following methods outlined in Richter and others (2006). The reservoir on the Moormans River will largely function as a passthrough facility, thereby maintaining natural flows in the river. By fully incorporating environmental flow needs into the water supply planning effort, the sizing of water infrastructure and development of the facility operations plan, including drought management, have been designed to meet both water supply and environmental flow needs.

\section{DISCUSSION AND SUMMARY}

In this paper we have outlined a number of ways in which dam operations, water use systems, and land management can be modified to restore environmental flows. We have highlighted some of the strategies that we have found to be most useful and applicable in many, if not all, parts of the world. However, we have not attempted an exhaustive coverage of the many ways in which flexibility to implement environmental flows can be realized. There is a great deal of innovation taking place in flow restoration below dams, and we hope that the growing toolbox of ideas will be widely disseminated. To this end, we have created a "Flow Restoration Database" on The Nature Conservancy's freshwater website (http://www.nature.org/initiatives/ freshwater/), which includes summaries of more than 850 flow restoration projects being undertaken around the world.

We believe that great opportunities for environmental flow restoration exist at virtually all of the world's 45,000+ large dams that are $>15 \mathrm{~m}$ height or capacity $>3 \times 10^{6} \mathrm{~m}^{3}$, and at hundreds of thousands of smaller dams. Many of the strategies discussed in this paper are equally applicable in the design of new dams. In fact, using these strategies and fully integrating environmental flow considerations in new dam designs will generally be much less expensive to implement, with less social and economic disruption as compared to dam re-operation efforts.

We do not wish to understate the challenges inherent in many dam re-operation projects. Some of the most commonly recurring constraints to dam reoperation include the following:

- In contrast to the considerable sums of money being made available for new dam construction, dam financiers and international development organizations have not provided adequate financial support for dam reoperation efforts. Until this imbalance is corrected, opportunities for implementing the approaches described in this paper in poor countries will be limited.

- Physical constraints posed by the dam infrastructure, especially the design of the outlet works, can severely limit the rate at which controlled water releases from a dam can be managed, making it difficult or impossible to release water of variable amounts ranging from low-flow to flood flow rates.

- Sediment trapping in reservoirs commonly produces highly modified sediment transport processes downstream of the dam. This often results in modified channel and floodplain geometry, or down-cut riverbeds, representing in many cases a fundamentally different physical habitat template to support native ecosystems. If some semblance of natural flow and sediment transport regimes including connections between the river and its floodplain cannot be maintained, restorationists must consider whether the ecosystem and species that can be supported by dam re-operation justify social and economic costs.

- Floodplain encroachment by roads, houses, and other structures, and various types of land use such as high-value agriculture may limit the feasibility of controlled reintroduction of floods, although some degree of high-flow restoration may be possible. 
- Unnaturally enhanced, higher than natural, water releases from dams are sometimes used to dilute downstream wastewater discharges. Restoring naturally low levels of flow can be quite difficult, if not impossible, in these instances due to concerns for human health.

- In many river basins, particularly in arid or semi-arid regions, virtually every drop of water has been allocated to human use, leaving very little if any for support of river ecosystems. The economic and cultural dependencies associated with existing patterns and volumes of water use can make it extremely difficult to make even small changes in dam operations.

- The benefits sought from dam re-operation can seldom be predicted with a high degree of certainty, and forecasts of a changing climate will add another element of risk. We have underscored the need to "assess results against goals" in our basic framework (Fig. 4), and we again emphasize that such adaptive management needs to be continuous and long term.

We have offered a rather simple framework in Fig. 4 for addressing these constraints and challenges. We believe that it is particularly important to strive for agreement among stakeholders concerning the goals of dam management and re-operation. We are living with a legacy of dams that were constructed to meet societal goals framed decades in the past. Today, society's goals for water management may be quite different, or at least more expansive, than those held by past generations. Concerns for environmental sustainability, and heightened attention to diverse stakeholder interests, are in many countries broadening discussions about water management goals. When public participation processes allow for the full expression of these modern goals, and when water managers are willing to try to accommodate them, we have found that technical obstacles can usually be relieved to better align dam operations with the will of the people.
Responses to this article can be read online at:

http://www.ecologyandsociety.org/vol12/iss 1/art12/responses/

\section{Acknowledgments:}

This paper is the product of more than two decades of designing and experimenting with strategies to improve dam operations for environmental and social benefits. All of this work has been done in close collaboration with our colleagues in The Nature Conservancy and the Natural Heritage Institute, as well as water and dam managers around the world. We continue to be inspired by their willingness to question traditional approaches and seek ways to integrate a fuller spectrum of human values into the governance and management of water.

\section{LITERATURE CITED}

Ahearn, D. S., R. W. Sheibley, and R.A. Dahlgren. 2005. Effects of river regulation on water quality in the lower Mokelumne River, California. River Research and Applications 21:651-670.

Anderson, M. T., and L. H. Woosley. 2005. Water availability for the western United States: key scientific challenges. U.S. Geological Survey Circular 1261, Denver, Colorado, USA.

Bunn, S. E., and A. H. Arthington. 2002. Basic principles and ecological consequences of altered flow regimes for aquatic biodiversity. Environmental Management 30:492-507.

Clarkson, R. W., and M. R. Childs. 2000. Temperature effects of hypolimnial-release dams on early life stages of Colorado River basin big-river fishes. Copeia 2000:402-412.

Collier, M., R. H. Webb, and R. H.Schmidt. 1996. Dams and rivers: primer on the downstream effects of dams. U.S. Geological Survey Circular 1126, Denver, Colorado, USA.

Dyson, M., G. Bergkamp, and J. Scanlon, editors. 2003. Flow: the essentials of environmental flows. IUCN, Gland, Switzerland. 
Fitzhugh, T. W., and B. D. Richter. 2004. Quenching urban thirst: growing cities and their impacts on freshwater ecosystems. BioScience 54:741-754.

Food and Agriculture Organization of the United States (FAO). 1995. Land and water integration and river basin management. Proceedings of an FAO informal workshop. Rome, Italy, 31 January-2 February 1993.

Gleick, P. H. 2000. The changing water paradigm: a look at twenty-first century water resources development. Water International 25:127-138.

Gleick, P. H., D. Haasz, C. Henges-Jeck, V. Srinivisan, G. Wolff, K. K. Cushing, and A. Mann. 2003. Waste not, want not: the potential for urban water conservation in California. Pacific Institute for Studies in Development, Environment, and Security, Oakland, California, USA.

King, J. M., C. Brown, and H. Sabet. 2003. A scenario-based holistic approach to environmental flow assessments for rivers. River Research and Applications 19:619-639.

Magilligan, F. J., K. H. Nislow, and B. E. Graber. 2003. Scale-independent assessment of discharge reduction and riparian disconnectivity following flow regulation by dams. Geology 31:569-572.

McCully, P. 1996. Silenced rivers: the ecology and politics of large dams. Zed Books, London, UK.

Millennium Ecosystem Assessment (MEA). 2005. Ecosystem services and human well-being: wetlands and water synthesis. World Resources Institute, Washington, D.C., USA.

Molden D., R. Tharme, I. Abdullaev, and R. Puskur. 2004. Water, food, livelihoods and environment: maintaining biodiversity in irrigated landscapes. Proceedings of International Ecoagriculture Conference and Practitioner's Fair, 27 September - 1 October 2004, Nairobi, Kenya.

Nilsson, C., C. A. Reidy, M. Dynesius, and C. Revenga. 2005. Fragmentation and flow regulation of the world's large river systems. Science 308:405-408.

Olsen, S. B., T. V. Padma, and B. D. Richter. 2006. A guide to managing freshwater inflows to estuaries.
University of Rhode Island, Coastal Resource Center, Providence, Rhode Island, USA.

Pearsall, S. H., III., B. J. McCrodden, and P. A. Townsend. 2005. Adaptive management of flows in the Lower Roanoke River, North Carolina, USA. Environmental Management 35:353-367.

Pillai, G. M., editor 1999. Challenges of agriculture in the 21st century. Maharashtra Council of Agricultural Education and Research, Shivajinagar, India.

Poff, N. L., J. D. Allan, M. B. Bain, J. R. Karr, K. L. Prestegaard, B. D. Richter, R. E. Sparks, and J. C. Stromberg. 1997. The natural flow regime: a paradigm for river conservation and restoration. BioScience 47:769-784.

Postel, S., and B. Richter. 2003. Rivers for life: managing water for people and nature. Island Press, Washington, D.C., USA.

Purkey, D. R., G. A. Thomas, D. K. Fullerton, M. Moench, and L. Axelrad. 1999. Feasibility study of a maximal program of groundwater banking in California. Natural Heritage Institute. Available online at www.n-h-i.org; www.conjunctiveuse.org.

Richter, B. D., J. V. Baumgartner, R. Wigington, and D. P. Braun. 1997. How much water does a river need? Freshwater Biology 37:231-249.

Richter, B. D., R. Mathews, D. L. Harrison, and R. Wigington. 2003. Ecologically sustainable water management: managing river flows for ecological integrity. Ecological Applications 13:206-224.

Richter, B. D., A. T. Warner, J. L. Meyer, and K. Lutz. 2006. A collaborative and adaptive process for developing environmental flow recommendations. River Research and Applications 22:297-318.

Rogers, K. H., and R. Bestbier. 1997. Development of a protocol for the definition of the desired state of riverine systems in South Africa. Department of Environmental Affairs and Tourism, Pretoria, South Africa.

Rosenberg, D. M., P. McCully, and C. M. Pringle. 2000. Global-scale environmental effects of hydrological alterations: introduction. BioScience 50:746-751. 
Shafroth, P. B., J. C. Stromberg, and D. T. Patten. 2001. Riparian vegetation response to altered disturbance and stress regimes. Ecological Applications 12:107-123.

The Nature Conservancy (TNC). 2005. User's manual for the indicators of Hydrologic Alteration (IHA) Software. The Nature Conservancy, Charlottesville, Virginia, USA. Available online at: http://www.nature.org/initiatives/freshwater/.

Tockner, K., and J. A. Stanford. 2002. Riverine floodplains: present state and future trends. Environmental Conservation 29:308-330.

Todd, C. R., T. Ryan, S. J. Nicol, and A. R. Bearlin. 2005. The impact of cold water releases on the critical period of post-spawning survival and its implications for Murray cod (Maccullochella peelii peelii): a case study of the Mitta Mitta River, southeastern Australia. River Research and Applications 21:1035-1052.

United Nations (UN). 2003. World population prospects: the 2002 revision. United Nations, New York, New York, USA.

UNEP/GRID-Arendal. 2002. Trends in water use, by sector, UNEP/GRID-Arendal Maps and Graphics Library, http://maps.grida.no/go/graphic/ trends in water use by sector.

Vickers, A. 2001. Handbook of water use and conservation. Water Plow Press, Amherst, Massachusetts, USA.

Vorosmarty, C. J., M. Meybeck, B. Fekete, K. Sharma, P. Green, and J. P. M. Syvitski. 2003. Anthropogenic sediment retention: major global impact from registered river impoundments. Global and Planetary Change 39:169-190.

Williams, G. P., and M. G. Wolman. 1984. Downstream effects of dams on alluvial rivers. U. S. Geological Survey Professional Paper 1286, Denver, Colorado, USA.

Willis, C. M., and G. B. Griggs. 2003. Reductions in fluvial sediment discharge by coastal dams in California and implications for beach sustainability. The Journal of Geology 111:167-182.

World Commission on Dams (WCD). 2000. Dams and development: a new framework for decision- making. Earthscan, London, UK.

World Wildlife Fund (WWF). 2004. Rivers at risk: dams and the future of freshwater ecosystems. Available online at: http://assets.panda.org/downloads/ riversatriskfullreport.pdf. 